\title{
Clinic Automation System: An Example of Medical Informatics
}

\author{
Rupali Jain \\ Associate System Engineer \\ IBM, Rajiv Gandhi Infotech Park, \\ Pune, Maharashtra, India
}

\begin{abstract}
This paper is proposed to serve as a facilitator for an application of Information filtering and retrieval in Medical 'Informatics. It is a rising specialty which links medicine and skill. With the extraordinary availability of digital information, retrieval and filtering are flattering important aspect of medical informatics. The author offers an impression of medical application for filtering and retrieval and brings in important state-of-the-art technique in a way that further adds to the knowledge in this field. This also provides a basis for the sympathetic issue and research development in this field. Clinic Automation System an example of medical informatics is described in this work. It offers a web based solution of Healthcare clinic and provides a user-centric solution for all the stakeholders involved, i.e., physicians, patients, salesman, and suppliers. In short it supports a part of the information infrastructure and workflow management to support the clinic eco-system.
\end{abstract}

\section{Keywords}

Information Retrieval, Information Filtering, Medical Informatics, Clinic Automation System

\section{INTRODUCTION}

Recent years have witnessed an impressive increase in web information. Figures from Google in official blog stated that the web pages indexed by Google number around 1 million in 1998, rapidly reached one billion in 2000, exceeded one trillion in 2008 and as per Google's latest report, this number has reached 60 trillion [1], [2]. Hence, advanced programs and formulas are required to understand what precisely users need and to transport the best results based on users' needs. In Healthcare domain, it is much more crucial to understand the user's information needs to be based on the most relevant information that can be found and delivered to the user. Thus, this is the primary objective of this paper.

The paper first focuses on a general background of Information Retrieval (IR) and Information Filtering (IF) to understand how the information is extracted accurately and efficiently. IR is the process of obtaining relevant information from a compilation of informational resources and IF is a system to remove redundant or unwanted information from an information or document stream based on document representations which represent users' interests. However, the main objective of this paper is to provide a sound understanding of Clinic Automation System (CAS) application in the field of medical informatics. Medical Informatics is the interdisciplinary study of the design, development, adoption and application of IT-based innovations in healthcare services delivery, management and planning [3]. The paper describes various aspects of CAS indepth. To this end, the paper is organized as follows: Section 2 reviews a conceptual background of IR and IF. The section extends till the description of differences between IR and IF; Section 3 presents an overview of CAS with objective, motivation behind the study and benefits of CA; Section 4 discusses the features, functional and non-functional requirements; Section 5 illustrates the architectural design in detail; and Section 6 summarizes the conclusions arising from the study.

\section{CONCEPTUAL BACKGROUND}

Mutually IF and IR are very vast areas that can be expansively explored, but in this work, a general description is presented with an aim to provide a knowledge base of both IR and IF. In addition, this section illustrates noticeable differences between IR and IF.

\subsection{IR Systems}

IR is finding material (classically documents) of an unstructured natural history (typically text) that satisfies an information requirement from within huge collections (typically stored on a computer) [4]. IR systems usually seek to find documents in a specified gathering that are associated to give information require. The information desire, which is dissimilar from IF, is articulated by a query that is generating by the user. The retrieval model uses the article indexes to retrieve the documents that expected to be relevant to the gathering that is associated with given information require and based on the searching and ranking methods. The score of each retrieved document is designed and the documents are rank according to this score. Lastly, the top Documents are obtainable to the end user according to the position scores. An IR system usually seeks to find documents in a specified order. It does not revisit information that is limited to a single object collection but matches more than a few objects which differ in the degree of relevancy to the query [5]. Figure 1 depicts information flow process in IR system.

\subsection{IF Systems}

IF has in recent times begun to be a focus for attention as a method for release of relevant information. IF systems wrap a broad range of domain, technology and method concerned in the process of revealing users to the information they need. An IF system can utilize a variety of related techniques to process information in dissimilar conduct and the general processes concerned in IF systems are depicted in Figure 2. The fundamental IF models are the user model and the filtering model. The user model Component clearly or completely gathers information from users and their information Requirements and can be constructed through dissimilar kind of learning models, and then process as an input to filter model. The filtering model is the spirit of IF system so as to matches the user profile through the represent data extract from the received document stream and then 
filters out the inappropriate documents. The basic choice mechanism can be dual or probabilistic [5]. doctors, patients, salesman, and suppliers can access through the internet.

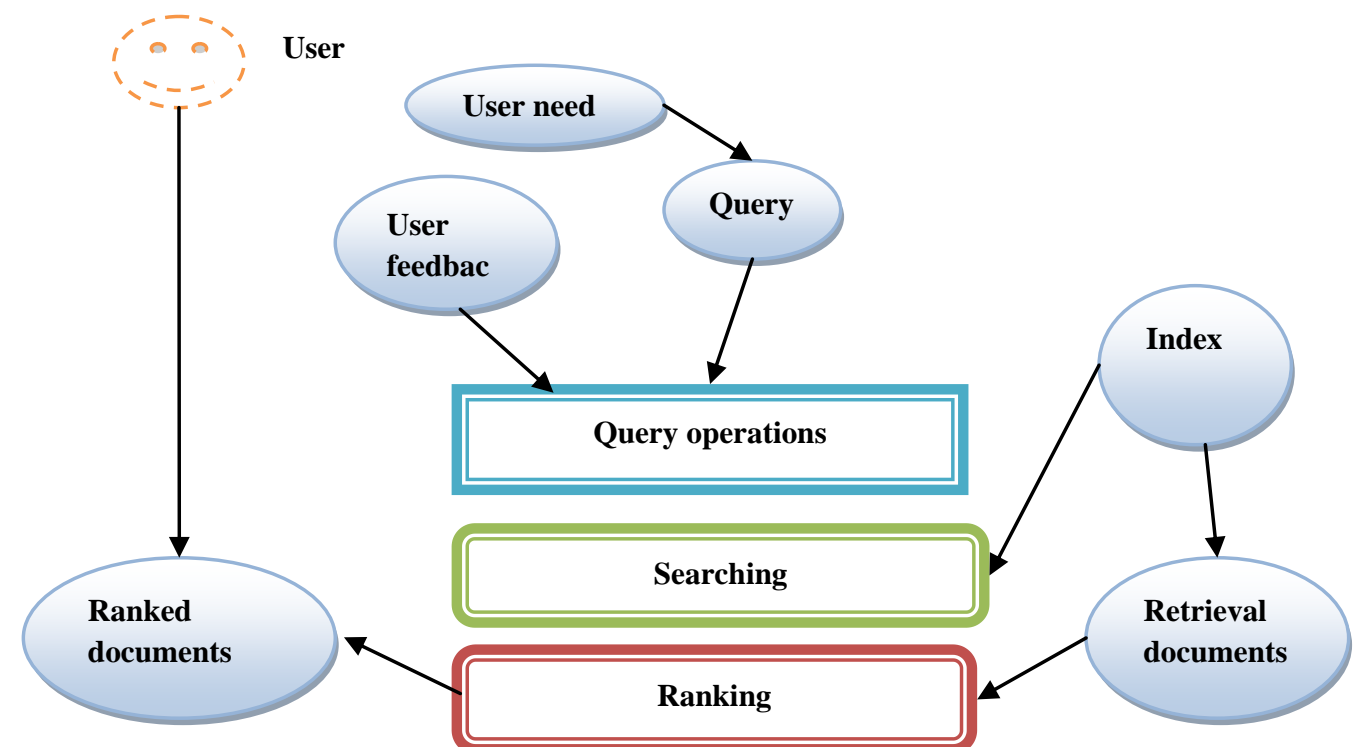

Fig 1: Process of an IR system [5]
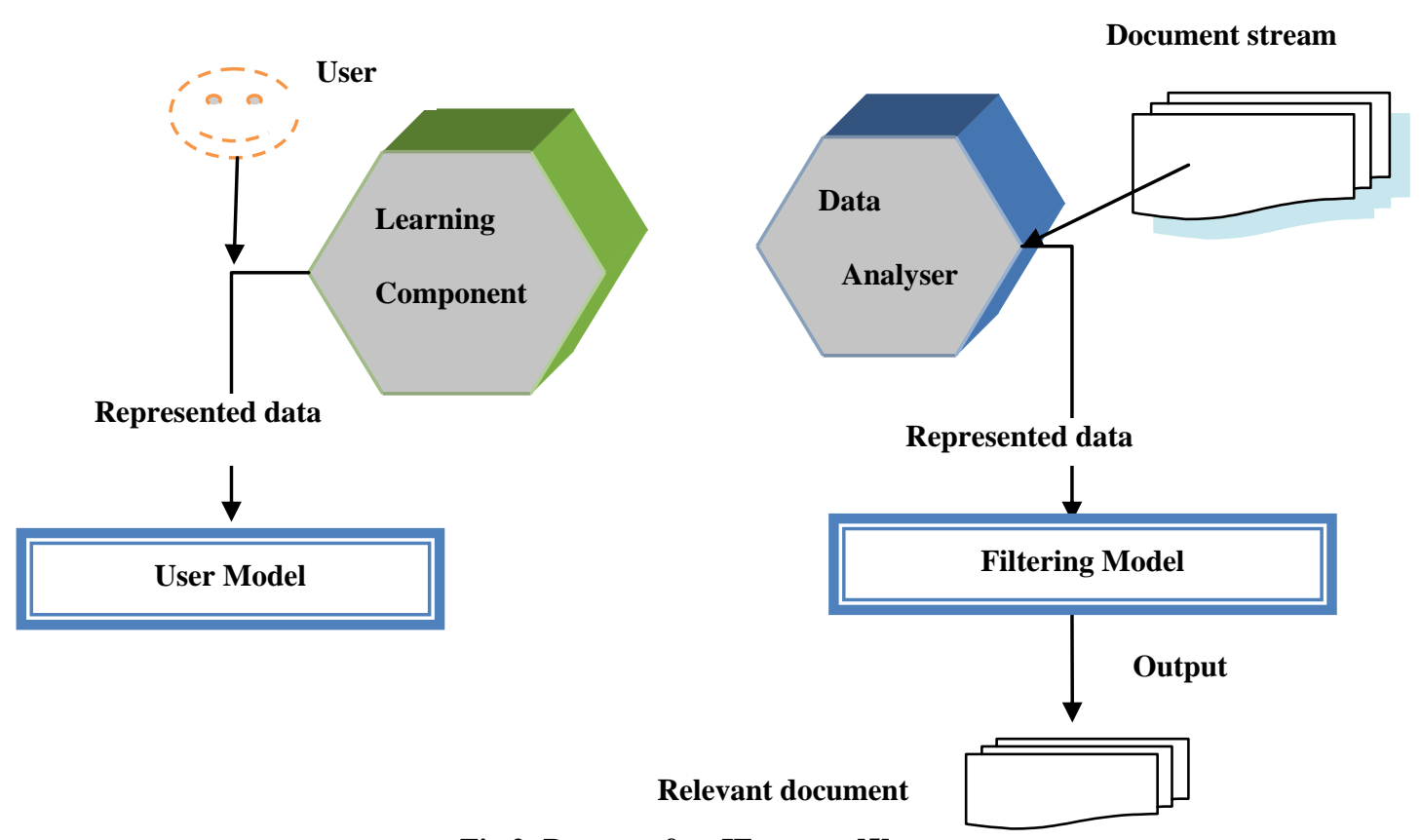

Fig 2: Process of an IF system [5]

\subsection{Difference between IR and IF}

IF and IR both have similar aims. Each wants to retrieve information according to the user request; they try to reduce as much as possible the quantity of irrelevant information. But, there are key differences among IR and IF, [5], as noted in Table 1.

\section{CAS- AN OVERVIEW}

\subsection{Objective}

The prime objective of CAS is to automate the operations of healthcare centers and make it available to a maximum number of users. This is a web based application which

\subsection{Motivation}

Healthcare center has been growing rapidly since decades. Healthcare industry is expected to touch US\$ 280 billion in India only [6]. Healthcare centers now employ a huge staff (full-time specialists, registered nurses, receptionist, and officers) and the number of patients is growing at a tremendously high rate. With industry developing, more problems have come out. 
Table 1. Difference between IF and IR

\begin{tabular}{|c|c|c|}
\hline Parameter & IR & IF \\
\hline $\begin{array}{c}\text { Frequency of } \\
\text { use }\end{array}$ & Ad-hoc use; queries & $\begin{array}{c}\text { Recurring use; } \\
\text { long term } \\
\text { users }\end{array}$ \\
\hline Goal & $\begin{array}{c}\text { Collection of relevant } \\
\text { data items for query }\end{array}$ & $\begin{array}{c}\text { Filtering out } \\
\text { irrelevant data } \\
\text { items or } \\
\text { collect data } \\
\text { items }\end{array}$ \\
\hline Dataset & Relatively static & $\begin{array}{c}\text { Very dynamic } \\
\text { Type of users }\end{array}$ \\
\hline $\begin{array}{c}\text { Not known to the } \\
\text { system }\end{array}$ & $\begin{array}{c}\text { Systems keep } \\
\text { user profiles }\end{array}$ \\
\hline system & $\begin{array}{c}\text { Anxious only with } \\
\text { the relevance of data } \\
\text { items }\end{array}$ & $\begin{array}{c}\text { Anxious also } \\
\text { with social } \\
\text { issues such as } \\
\text { user modeling } \\
\text { and privacy }\end{array}$ \\
\hline
\end{tabular}

Let's consider an anonymous health clinic in a rural area without an automatic retrieval system, the problems it may face are: the receptionist might have overwhelmed by phone calls. Many phone calls are from patients who want to get information about the prescribed drugs. Some patients want to consult with the doctors. It takes a long time for the receptionist to check if these patients are existing patients. The clinic wants to offer a free consultation to its patients only. Also, the clinic wants to learn that the drugs they want to prescribe are (nearly) out of stock, and what the prices of drugs in the current market are. After the purchase order is made, when the drugs arrive or the orders are not placed in a timely manner, this make sale department officer take a lot of time to contact suppliers.

To alleviate the problems faced due to manual operations and yet continue to offer outstanding service to patients, here are some issues, findings, and proposed solutions:

- A significant number of calls from patients relate to the drugs information. Since such information rarely, if ever, changes, it is a waste of time for doctors to give the same information to different patients. So, information about these drugs should be available on the website.

- To facilitate communication between patients and doctors, they should be able to contact on the Web. Email addresses can be used for this purpose. However, email privacy is a concern. As some patients may misuse the doctors' email addresses. Therefore, a "private message box" can be set up for each doctor and patient. This way, doctors, and patients can leave and send messages to one another without revealing their email addresses.

- Although it is relatively rare that drug orders are lost or are not placed on time, this problem is troublesome. Part of the success any clinic is its ability to offer low prices on drugs to its patients. When some patients need the drugs immediately due to the severity of their symptoms, but no such drugs are available, patients have to purchase the drugs from a pharmacy at higher prices. Currently, all the drug suppliers for the clinic say that they have salespeople who visit their customers' websites daily for taking orders. It is a valuable service though the clinic cannot take advantage due to its lack of internet presence. Once a website has been set up, the doctors (not the receptionist) can order whatever drugs they need using the clinic website. This way, the orders will be processed within 24 hours by a supplier.

\subsection{Benefits}

The CAS has several merits. Firstly, automates the manual efforts of employees and provides effective management. Secondly, it provides faster response time. Thirdly, many users are managed efficiently. Lastly, medicine stocks remain updated regularly as it is direct tracked by the sales team.

\section{CAS - DESCRIPTION 4.1 Features}

Different components of the web-based system, their properties and features are described in figure 3 and table 2 .

\subsection{Functional Requirements}

The web application should have the main modules as:

- Visitor: A user who is not registered can view the drugs information and Physician information. The visitor may be patient, doctor or any web surfer. The User can browse to the home page and view-

\section{$\checkmark \quad$ View Medicine Information \\ $\checkmark \quad$ View Physician information}

- Patient: A user who is registered as a Patient. The Patient's page and the pages to which it links help the patient do such things as -

\section{$\checkmark \quad$ Edit Patient Profile (except Name) \\ $\checkmark \quad$ Leave Message \\ $\checkmark \quad$ Retrieve Message}

- Doctor: A user who is registered as a Doctor. The Doctor's page and pages to which it links help the participant do activities like -

\section{$\checkmark \quad$ View Patient Records \\ $\checkmark$ Leave Message \\ $\checkmark$ Retrieve Message \\ $\checkmark$ Order Drugs \\ $\checkmark \quad$ Check Order Status}

- Salesman: A user who is registered as a Salesman. The Salesman's page and pages to which it links help the salesman do activities like -

\section{$\checkmark \quad$ View current stock of Drugs \\ $\checkmark$ Order Drugs \\ $\checkmark \quad$ Leave Message \\ $\checkmark \quad$ Retrieve Message \\ $\checkmark \quad$ Check order status}

- Supplier: A user who is registered as Supplier. The Supplier's page and pages to which it links help the supplier do activities like -
$\checkmark$ Retrieve Message
$\checkmark \quad$ Leave Message
$\checkmark$ View Quotation / Order
$\checkmark \quad$ Save Order 


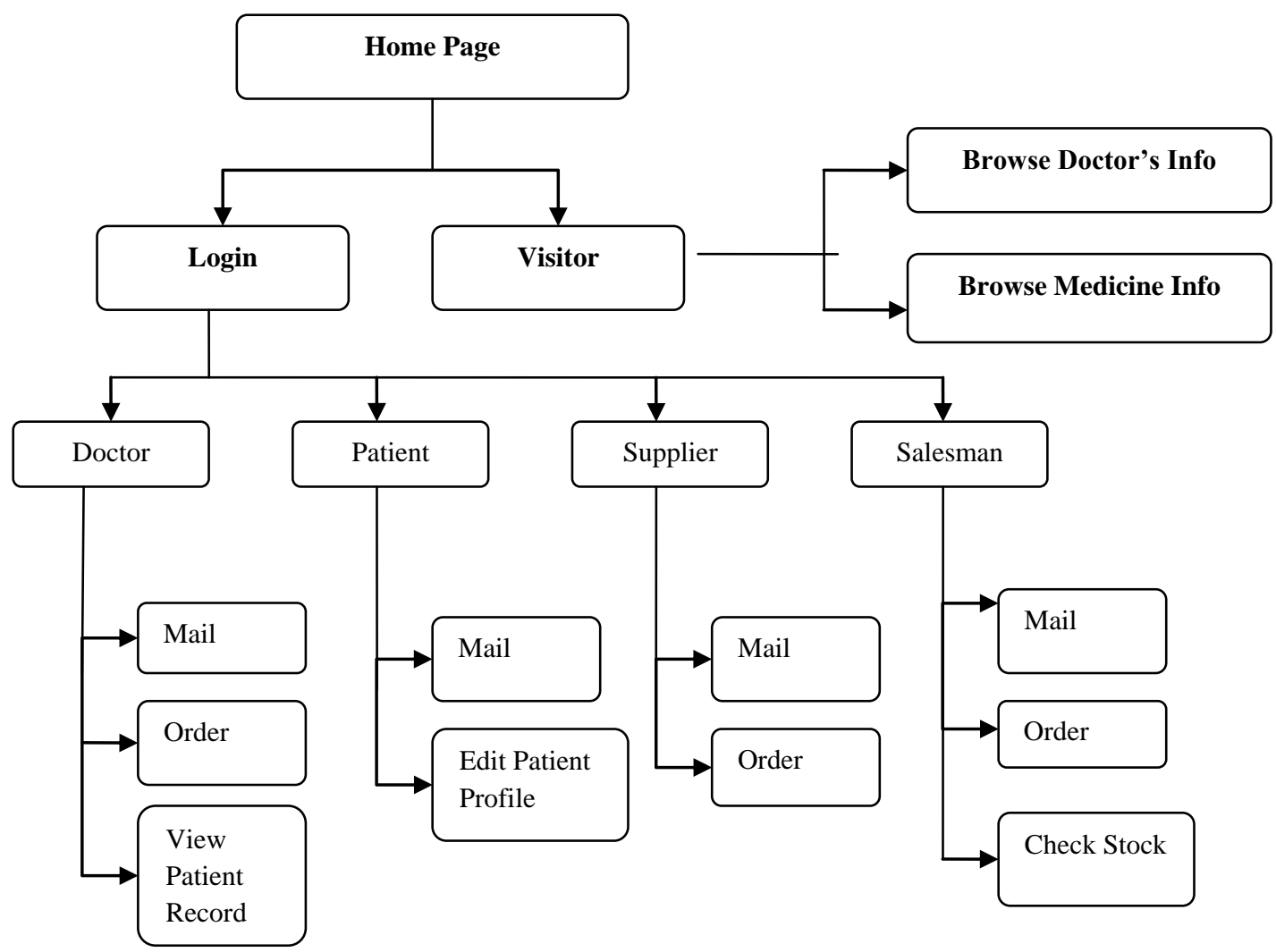

Fig 3: Flow diagram of different CAS component

Table 2. Different needs and concern of stakeholders

\begin{tabular}{|c|c|c|}
\hline Stakeholder & Needs & Concerns \\
\hline Patient & $\begin{array}{l}\text { The patient wants to communicate with a doctor by } \\
\text { sending a message. } \\
\text { Browse information about drugs } \\
\text { Edit personal information }\end{array}$ & $\begin{array}{l}\text { Difficult to contact doctor every } \\
\text { time for drug inquiry or any } \\
\text { other information. }\end{array}$ \\
\hline Doctor & $\begin{array}{l}\text { Doctor need to read patient's queries and reply back. } \\
\text { Place an order for the drugs he requires. } \\
\text { View records of his or her patients. }\end{array}$ & $\begin{array}{l}\text { Difficult to get information } \\
\text { about a patient who has called. } \\
\text { It is a waste of time for doctors } \\
\text { to give the same drug's } \\
\text { information to different patients }\end{array}$ \\
\hline Salesman & $\begin{array}{l}\text { Can take the orders placed by doctors directly from the } \\
\text { website and place the order. } \\
\text { Can leave and retrieve the message from the mailbox. }\end{array}$ & $\begin{array}{l}\text { The problem of drugs not } \\
\text { available or supplied in time } \\
\text { will overcome. }\end{array}$ \\
\hline Drug Supplier & $\begin{array}{c}\text { A supplier shall be able to query if the clinic has any } \\
\text { drug order. In case of questions or comments, a } \\
\text { supplier shall be able to leave messages for the } \\
\text { physician who has placed the order }\end{array}$ & $\begin{array}{l}\text { Reduces efforts of sales } \\
\text { department office to contact the } \\
\text { supplier for supplying orders at } \\
\text { a right time. }\end{array}$ \\
\hline Visitor & $\begin{array}{l}\text { Visitor shall be able to browse the information on } \\
\text { drugs and physicians. }\end{array}$ & To get information about clinic \\
\hline
\end{tabular}

\subsection{Non-Functional Requirements}

Different non-functional requirements are listed below:

\section{- Usability}

For maximum accessibility, the system interface shall not use HTML frames but it shall be accessible by any forms-capable browser that supports the use of 〈table> tag. The interface should be simple and yet can easily be navigated even by inexperienced Web users.

\section{- Performance}

The Web server shall be able to handle at least 30 simultaneous user sessions. The system shall require no more than 5 seconds to retrieve and to respond to a client's request for a static Webpage. Also, it shall require no more than 10 seconds to respond to a dynamic Webpage. However, in case of operations that may take longer than the specified period, users shall be notified in advance accordingly. 


\section{- Robustness \& Reliability}

For robustness, the data entered by the user shall be checked on the client side. In the case of data entry errors, helpful messages shall be displayed so that the user understands the cause of the errors. The maximum acceptable downtime for maintenance and upgrade shall not exceed more than two hours a week.

\section{- Security}

The system must ensure that only authorized people can view or update records strictly based on the functional requirements. Only an existing patient of the clinic shall be able to edit his or her profile and leave messages to and retrieve messages from a doctor. Only doctors are authorized to edit his or her patients' profiles, order drugs, check order status and leave messages to and retrieve messages from patients. Only a supplier is authorized to take orders online and may leave a message regarding the order to the doctor who has placed the order. "Outsiders" shall be able to view drug and physician information only.

\section{- Hardware}

Any browser-enabled computer system with TCP/IP connection or dial-up connection to an ISP shall be able to use the system. In particular, the browser shall be a standard HTTP-3.2 capable web browser.

\section{CAS - ARCHITECTURE OVERVIEW}

\subsection{Features}

The purpose of this section is to describe the in general architecture plan at the component level. Table 3 outlines the major components of the system.

Table 3. Different functionalities of CAS components

\begin{tabular}{|c|c|}
\hline Component & Description \\
\hline User manager & User management functionality \\
\hline $\begin{array}{c}\text { Drug } \\
\text { Manager }\end{array}$ & $\begin{array}{c}\text { Functionality related to managing user } \\
\text { profiles }\end{array}$ \\
\hline $\begin{array}{c}\text { Order } \\
\text { Manager }\end{array}$ & $\begin{array}{c}\text { All functionality related to managing the } \\
\text { orders }\end{array}$ \\
\hline Mail Manager & $\begin{array}{c}\text { All functionality related to managing user } \\
\text { communication }\end{array}$ \\
\hline
\end{tabular}

\subsection{Logical View of the Component Architecture}

The diagram (Figure 4) below outlines the logical view of the web application. It depicts the separation of the layers and the major components in each layer.

The architecture outlined above defines 4 tiers.

- Presentation \& Business Logic Tier. This tier will be implemented using JSP / Servlet which is based on MVC design pattern. The appearance tier collects user input, present data, controls page direction-finding, and delegates user input to the business-logic tier. The appearance tier can also validate user input. A servlet middle layer shall be masking any request. This filter shall be responsible for authenticating the request, logging the start of any request and uphold the application assembly state. Here the Business logic ought to be implementing as part of the repair Bean, which shall have the business operation to perform and related logic. A common explain template shall be used for scheming the pages.
- Data Access Tier. This will be implemented using Data access objects, which shall have the data access logic.

- Data Persistence tier. This will consist of the physical database (Oracle)

\subsection{Architectural Decisions}

The Architectural Decisions document significant decisions concerning any aspect of the structural design counting the structure of the system, the stipulation and allocation of function, the background fitness of the system and obedience to standards. Structural design is understood partly through the record of the significant decisions made during its development. A well-documented structural design includes its own good reason and evaluation criteria. The justification and assessment criteria may be recorded next to the decision or, at least in part, by orientation to more generally applicable principles, policies, and guidelines, which are established in other work produced or in external references.

Following are key architectural decisions:

1. Struts Tiles was consideration of for scheming the Common explain of the pages (Struts framework was to be used in this case), but to keep it in the servlet JSP world, simple JSP comprises shall be used.

2. To build the appearance layer, servlet/JSP were compared with the JSF, and it was determined to use servlets and JSP to keep the structural design simple. This was done keeping in mind the project time constraint and to have a zero learning curve. The meaning was to focus on the concept and not the framework.

3. For database perseverance layer, use of JDBC from easy Data access object is favored to Hibernate this was done custody in mind the project time constraints and to have a zero knowledge curve. The meaning was to focus on the concepts and not the framework.

4. The Eclipse IDE (Europe or Ganymede versions) is supposed to be used for growth. Tomcat shall be plug into Eclipse. Eclipse-tomcat duo is kept keeping in mind the project time constraint and to have a zero knowledge curve

5. CVS should be second-hand as the code versioning scheme for Configuration Management. It is projected to plug-in the CVS to Eclipse. This will supply good simulation of the real-time expansion environment where developers require working on a large development project.

\section{CONCLUSION}

The main motive of this work is to pinpoint the highlights of IR and IF, and to draw a comprehensive picture of the methodology behind Clinic Automation, a web application based medical informatics system. This paper begins with an overview of IF and IR. It seems fair to say, after examining 


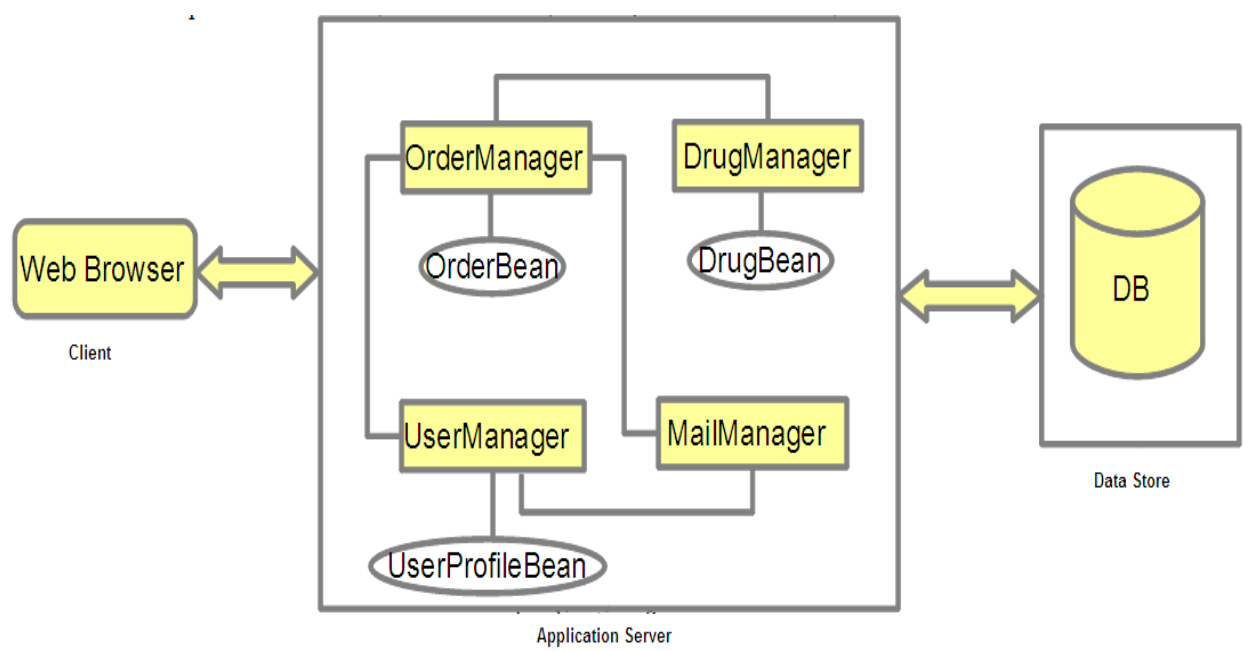

Fig 4: Logical view of CAS

the basics of these subjects, that there is the comparatively little difference between the two at an abstract level. The presented study did not cover all the aspects of IF and IR like the technical details, different classification models, etc. The study then details the CAS and its different components. For the state-of-art information regarding the field of medical informatics, readers are advised to refer handbook of medical informatics [7].

The CAS is a web-based database of various activities of agents related to the healthcare centers. The objective of this system is to deliver the requirements of a healthcare system. The paper details the complete design of CAS, its functional and non-functional requirements, different components and their properties. The CAS simplifies the task and reduces the paperwork. It enhances and upgrades the current system, automates almost all the activities of manual work, provides quick and accurate information, it has a very friendly user interface and reduces the overall cost.

\section{ACKNOWLEDGMENT}

The described study is part of training the author received at IBM, Pune, India. The author would like to thank Anshuman Sharma ( $\mathrm{PhD}$, Australia) for giving valuable inputs. In addition, the author acknowledges the anonymous reviews for insightful comments.

\section{REFERENCES}

[1] We knew the web was big. 2008. Official Google Blog. (accessed 13.1.16)

[2] How Search Works - The Story - Inside Search - Google http://www.google.com/insidesearch/howsearchworks/th estory/ (accessed 20.1.16).

[3] Medical Informatics. HiMSS transforming health through IT. http://himss.org/clinical-informatics/medicalinformatics (accessed 20.1.16)

[4] Manning, C.D., Raghavan, P., and Schütze, H. 2008. Introduction to information retrieval. Cambridge university press Cambridge.

[5] Gao, Y. 2015. Pattern-based topic modelling and its application for information filtering and information retrieval ( $\mathrm{PhD}$ Thesis). Queensland University of Technology, Brisbane,Queensland.

[6] Healthcare Industry in India. Indian Healthcare Sector Services. http://www.ibef.org/industry/healthcareindia.aspx (accessed 25.1.16).

[7] Horton, C. 2015. Handbook of Medical Informatics. Foster Academics. 